\title{
Metabolic Engineering for Improved Fermentation of L-Arabinose
}

\author{
Suji Ye, Jeong-won Kim, and Soo Rin Kim* \\ School of Food Science and Biotechnology, Kyungpook National University, Daegu 41566, Republic of Korea
}

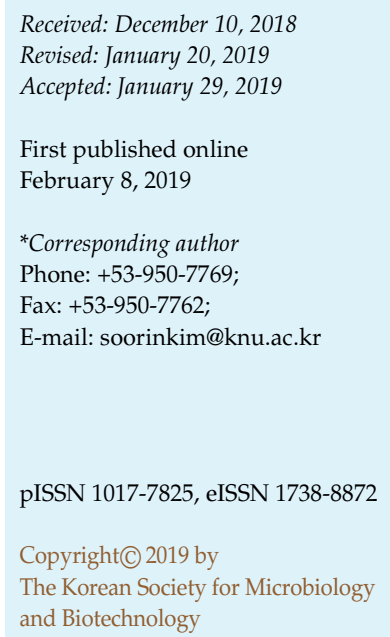

\begin{abstract}
L-Arabinose, a five carbon sugar, has not been considered as an important bioresource because most studies have focused on D-xylose, another type of five-carbon sugar that is prevalent as a monomeric structure of hemicellulose. In fact, L-arabinose is also an important monomer of hemicellulose, but its content is much more significant in pectin (3-22\%, g/g pectin), which is considered an alternative biomass due to its low lignin content and mass production as juiceprocessing waste. This review presents native and engineered microorganisms that can ferment L-arabinose. Saccharomyces cerevisiae is highlighted as the most preferred engineering host for expressing a heterologous arabinose pathway for producing ethanol. Because metabolic engineering efforts have been limited so far, with this review as momentum, more attention to research is needed on the fermentation of L-arabinose as well as the utilization of pectin-rich biomass.
\end{abstract}

Keywords: L-Arabinose, pectin, metabolic engineering, Saccharomyces cerevisiae, pentose

\section{Significance of L-Arabinose as a Bioresource}

Bioconversion of lignocellulosic biomass such as agricultural residues and wood waste materials into fuels and value-added chemicals is technically challenging due to a variety of factors [1-4]. Lignocellulosic biomass is composed of $40-50 \%$ cellulose, $25-30 \%$ hemicellulose, and 15-20\% lignin, and the high lignin content requires strong physical and chemical pretreatment for its decomposition [5]. Also, hemicellulose is hydrolyzed into a mixture of glucose, xylose, and other minor sugars such as Larabinose, and their fermentation is not efficiently done by any native industrial microorganisms [6]. For these reasons, industrial bioprocesses utilizing lignocellulosic biomass have not been realized so far, and the search for other alternative renewable biomass continues [7-10].

Meanwhile, fruit processing wastes such as orange peels are becoming abundant with the growth of the fresh juice industry, but are not being efficiently utilized [11, 12]. Fruit processing wastes are high in pectin $(12-35 \%, \mathrm{~g} / \mathrm{g}$ dry weight) with much less lignin content (approximately $2 \%$, $\mathrm{g} / \mathrm{g}$ dry weight) than lignocellulosic biomass [13]. Therefore, this pectin-rich biomass can be easily broken down into monomers; however, pectin monomers, like hemicellulose monomers, are not easily metabolized by common industrial hosts [14].

The primary chemical structure of pectin is methylated polygalacturonic acid in an alpha-(1-4) chain with branched oligosaccharides consisting of arabinose, galactose, xylose, and some minor sugars [15]. Among them, L-arabinose is one of the most abundant pentose sugars in pectin [16]. Arabinose content in various fruits and vegetables ranges from 3.3 to $21.6 \mathrm{~g} / 1$ (summarized in Table 1) [14, 17, 18]. It is contradictory to lignocellulosic biomass which has limited arabinose content (approximately 0.2\%, g/g dry weight) [19].

L-Arabinose is a five-carbon sugar like xylose. Unlike other sugars that naturally occur in the D-form, such as D-xylose, L-arabinose is a component of pectin and hemicellulose, and it is more common than D-arabinose in nature. Although studies have been conducted extensively for xylose metabolism to realize lignocellulosic bioprocesses [20], L-arabinose metabolism has not received much attention. In the present review, microbial strains that can natively metabolize L-arabinose are summarized. In some studies, the strains were engineered to produce useful products such as ethanol. Moreover, metabolic engineering efforts to develop efficient L-arabinose-fermenting strains 
Table 1. Representative pectin-rich biomass and their arabinose content.

\begin{tabular}{|c|c|c|c|}
\hline Source & Arabinose, $\%{ }^{1)}$ & Other major sugars ${ }^{2}$ & Refs \\
\hline Sugar beet pulp & $21.6(0.28)$ & Glu & {$[17,18]$} \\
\hline Lime peel & 8.5 & Glu & [14] \\
\hline Pear peel & 6.0 & Glu, Xyl, Fru & [14] \\
\hline Orange peel & $5.6(0.20)$ & Glu, Fru & {$[14,17]$} \\
\hline Apple pomace & 5.5 & Glu, Fru, Suc & [14] \\
\hline Mandarin peel & 3.3 & Glu, Fru, Suc & [14] \\
\hline
\end{tabular}

1)\% Dry matter (g/g pectin).

${ }^{2)}$ Higher content than arabinose. Glu, Glucose; Xyl, xylose; Fuc, Fucose; Suc, Sucrose.

using non-native but industrial hosts are discussed, focusing on Saccharomyces cerevisiae.

\section{Native L-Arabinose-Fermenting Microorganisms}

Arabinose catabolic pathways of native strains can be divided into the oxidoreductase (fungal) and isomerase (bacterial) pathways (Fig. 1). In both pathways, L-arabinose is converted into D-xylulose-5-phosphate, which is then canonically metabolized by the non-oxidative pentose phosphate pathway [21], or alternatively by the phosphoketolase pathway such as that in Clostridium acetobutylicum [22].

In L-arabinose-fermenting native fungi, L-arabinose is converted into D-xylulose by two reduction and two oxidation reactions, which are composed of $\mathrm{NAD}(\mathrm{P}) \mathrm{H}$ specific aldose reductase (AR or $\mathrm{XR}), \mathrm{NAD}^{+}$-specific Larabitol-4-dehydrogenase (LAD), NAD(P)H-specific L-xylose reductase (LXR or ALX), and NAD ${ }^{+}$-specific xylitol dehydrogenase $(X D H)$ [21]. Then, D-xylulose is phosphorylated into D-xylulose-5-phosphate by D-xylulokinase (XK). As highlighted in Fig. 1, fungal pathways of L-arabinose and D-xylose share three enzymes: AR (XR), XDH and XK. Although the cofactor preferences of AR and LXR (ALX) vary among fungal species, the first reductase enzyme usually prefers NADPH, while the two dehydrogenases strictly use $\mathrm{NAD}^{+}$. Therefore, redox balance of the pathway leading to efficient cell growth is achieved under aerobic conditions [23, 24]. Under oxygen-limited conditions, Larabitol might be produced due to $\mathrm{NAD}^{+}$limitation, which is not found in the bacterial pathway of L-arabinose metabolism [25-27]. Because of the oxygen-dependent nature of the fungal pathway, ethanol production by these native strains is marginal [28, 29].

As early as 1990, a few native arabinose-fermenting fungi strains were identified, but the strains yielded a trace level of ethanol or even no ethanol production [26, 28]. In detail,
116 different yeast strains were screened for the ability to catabolize arabinose or xylose aerobically. As a result, four yeast strains (Ambrosiozyma monospora, and three Candida spp.) were found to ferment L-arabinose as a sole carbon source. Additionally, the ethanol yield was at most $0.18 \mathrm{~g} / \mathrm{g}$

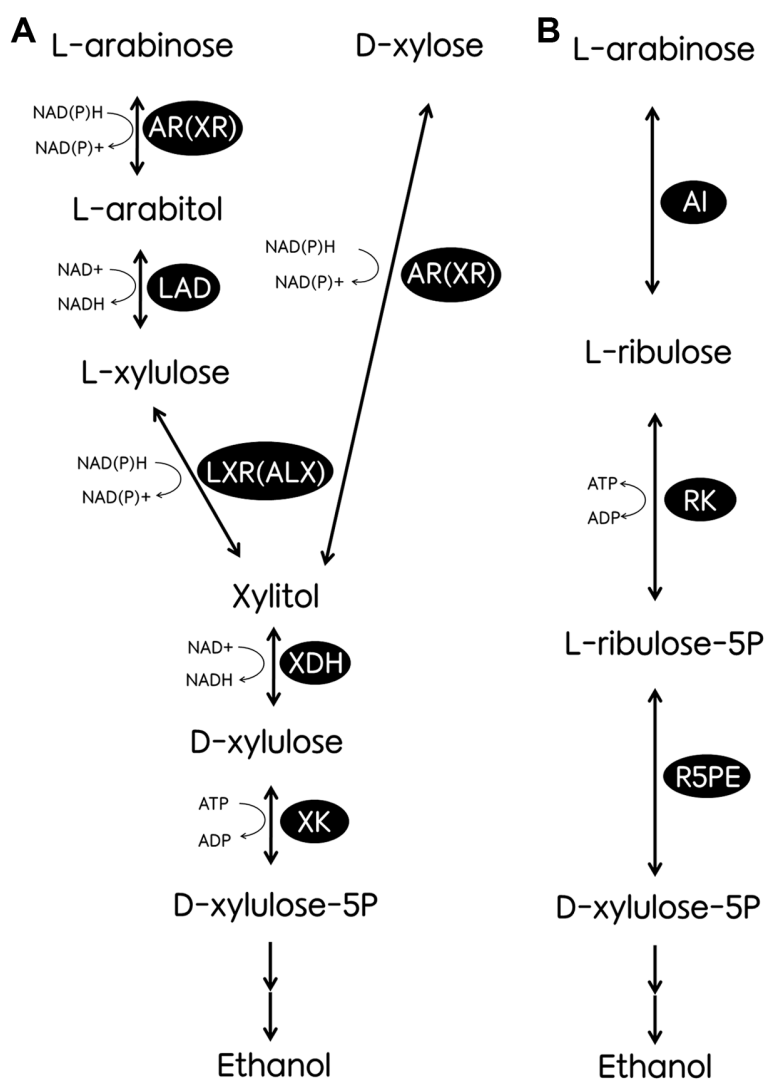

Fig. 1. Arabinose metabolic pathways in fungi (A) and bacteria (B).

$\mathrm{AR}(\mathrm{XR})$; Aldose reductase, LAD; L-arabitol-4-dehydrogenase, LXR(ALX); L-xylulose reductase, $\mathrm{XDH}$; D-xylulose reductase, $\mathrm{XK}$; Xylulokinase, AI; L-arabinose isomerase, RK; L-Ribulokinase, R5PE; L-Ribulose-5-P-4-epimerase. 
Table 2. Native arabinose-assimilating microorganisms and their engineered strains producing ethanol.

\begin{tabular}{|c|c|c|c|c|c|c|}
\hline \multirow{2}{*}{ Strain } & \multirow{2}{*}{ Genotype $^{1)}$} & \multicolumn{2}{|c|}{ Fermentation conditions ${ }^{2}$} & \multicolumn{2}{|c|}{ Ethanol production } & \multirow{2}{*}{ Refs } \\
\hline & & Arabinose $(\mathrm{g} / \mathrm{l})$ & Aeration & Titer $(\mathrm{g} / \mathrm{l})$ & Yield (g/g) & \\
\hline \multicolumn{7}{|l|}{ Yeast } \\
\hline Ambrosiozyma monospora Y-1484 & Wild type & 80 & OL & 4.1 & 0.18 & [28] \\
\hline Candida succiphila Y-11998 & Wild type & 80 & OL & 3.9 & 0.05 & [28] \\
\hline \multicolumn{7}{|l|}{ Bacteria } \\
\hline Sarcina ventriculi & Wild type & 19 & AN & 4.7 & 0.31 & [31] \\
\hline Klebsiella oxytoca P2 & $Z m \_p d c, Z m \_a d h B$ & 80 & OL & 27.2 & 0.34 & [32] \\
\hline Escherichia coli FBR3 & $Z m \_p d c, Z m \_a d h B, l d h \Delta, p f l \Delta$ & 100 & OL & 44.4 & 0.46 & [33] \\
\hline
\end{tabular}

${ }^{1)} \mathrm{Zm}$, Zymomonas mobilis; $p d c$, pyruvate decarboxylase gene; $a d h B$, alcohol dehydrogenase gene; $l d h$, lactate dehydrogenase gene; $p f l$, pyruvate formate lyase gene.

${ }^{2)}$ All fermentations were performed with complex media with an initial arabinose concentration as shown above. Arabinose was the only carbon source available. OL, oxygen-limited conditions; AN, anaerobic conditions.

consumed arabinose) with A. monospora and C. succiphila (Table 2).

Meanwhile, 15 xylose-fermenting microorganisms were screened to evaluate the ability to ferment L-arabinose to ethanol [26]. As a result, one bacterium (Erwinia chrysanthemi), six yeast strains (C. tropicalis, C. shehatae, Pachysolen tannophilus Y-2460, P. tannophilus Y-12891, Scheffersomyces stipitis, and Torulopsis sonorensis), and one mold strain (Aspergillus oryzae) were confirmed to assimilate arabinose with xylose and glucose as co-substrates. While E. chrysanthemi and C.tropicalis consumed xylose and arabinose simultaneously, all other fungal strains preferred xylose over arabinose. During arabinose metabolism, $S$. stipitis was the only fungal strain producing ethanol at a yield of 0.15 (g/g consumed sugar) and arabitol at a yield of 0.24 ( $\mathrm{g} / \mathrm{g}$ consumed sugar).

In comparison to the above-mentioned fungal pathways, bacterial pathways of L-arabinose metabolism are relatively simple; 1 ) only three enzymes are needed to convert to D-xylulose-5-phosphate, and 2) no cofactor is involved. The bacterial pathway consists of L-arabinose isomerase (AI), L-ribulose kinase (RK), and L-ribulose-5-phosphate-4epimerase (R5PE) encoded by the ara $A$, araB, and araD genes, respectively (Fig. 1B) [30]. In addition, native bacterial strains such as Sarcina ventriculi can ferment L-arabinose anaerobically and produce ethanol efficiently at a yield of 0.3 (g/g consumed arabinose) [31]. For some bacterial strains lacking the $p d c$ and $a d h$ genes (encoding pyruvate decarboxylase and alcohol dehydrogenase, respectively) such as Klebsiella oxytoca, introducing the genes from Zymomonas mobilis enabled ethanol fermentation from Larabinose [32]. For native L-arabinose-metabolizing Escherichia coli, in contrast, deletion of lactate dehydrogenase $(l d h)$ and pyruvate formate lyase $(p f l)$ genes was required to enable ethanol production from L-arabinose [33]. As summarized in Table 2, native bacterial strains assimilating L-arabinose can be promising hosts for ethanol fermentation.

\section{Engineering Saccharomyces cerevisiae for L-Arabinose Fermentation}

S. cerevisiae, the industrial host for bioethanol production, cannot utilize L-arabinose as efficiently as it can utilize xylose. For cellulosic ethanol production, a great amount of effort has been focused on the development of xylosefermenting $S$. cerevisiae strains, while there have not been many examples for L-arabinose.

There are a limited number of studies on the development of $S$. cerevisiae expressing a heterologous fungal pathway of L-arabinose metabolism compared to that expressing a heterologous bacterial pathway [30, 34-38]. Usually, xylosefermenting $S$. cerevisiae expressing heterologous $\mathrm{AR}, \mathrm{XDH}$, and $\mathrm{XK}$ is first engineered by expressing Scheffersomyces stipitis XYL1, XYL2, and XYL3 genes, respectively, in most cases [20]. It has to be noted that an $\mathrm{AR}$ is $\mathrm{NAD}(\mathrm{P}) \mathrm{H}-$ specific aldose reductase with specificity for both xylose and L-arabinose [39] with a 50\% higher rate for L-arabinose metabolism when using NADPH as a cofactor [40]. Next, the resulting strain is further engineered to express LAD and LXR, which are T. reesei LAD1 and A. monospora ALX1 genes, respectively $[24,34]$. The $S$. cerevisiae $424 \mathrm{~A}(\mathrm{LNH}-$ $\mathrm{ST}) / \mathrm{pLXR}_{\mathrm{NAD}} \mathrm{LAD}$ strain, which was developed as above, produced $10 \mathrm{~g} / 1$ ethanol from $45 \mathrm{~g} / 1$ L-arabinose [35] as summarized in Table 3 . In another study, T. reesei LXR1 gene was expressed instead of $A$. monospora ALX1 gene, but the resulting strain only produced $0.1 \mathrm{~g} / 1$ ethanol from $50 \mathrm{~g} / 1 \mathrm{~L}$-arabinose $[35,41]$. The low ethanol production can be explained by the fact that $T$. reesei LXR1 gene is now 
Table 3. Ethanol fermentation by engineered Saccharomyces cerevisiae using arabinose as the sole carbon source.

\begin{tabular}{|c|c|c|c|c|c|c|c|c|c|}
\hline Strain names & $\begin{array}{c}\text { Strain } \\
\text { backgrounds }\end{array}$ & Arabinose pathways & Optimization strategies & Media & $\begin{array}{c}\text { Arabinose } \\
(\mathrm{g} / \mathrm{l})\end{array}$ & Aeration & $\begin{array}{l}\text { Titer } \\
(\mathrm{g} / \mathrm{l})\end{array}$ & $\begin{array}{c}\text { Yield } \\
\text { (g/g } \\
\text { consumed) }\end{array}$ & Refs \\
\hline \multicolumn{10}{|c|}{ Heterologous fungal pathways } \\
\hline $\mathrm{H} 2561$ & CEN.PK2 & $\begin{array}{l}\text { Ss XYL1, SsXYL2, } \\
\text { ScXKS1, TrLAD1, } \\
\text { TrLXR1 }\end{array}$ & - & Minimal & 50 & AN & 0.1 & - & [34] \\
\hline $\begin{array}{l}424 \mathrm{~A}(\mathrm{LNH}-\mathrm{ST}) / \\
\mathrm{pLXR}_{\mathrm{NAD}}-\mathrm{LAD}\end{array}$ & $424 \mathrm{~A}$ & $\begin{array}{l}\text { Ss } X Y L 1, \text { Ss } X Y L 2, \\
\text { Ss } X Y L 3, \operatorname{Tr} L A D 1 \\
\text { Am } A L X 1\end{array}$ & - & Complex & 45 & OL & 9.4 & 0.22 & [35] \\
\hline \multicolumn{10}{|c|}{ Heterologous bacterial pathways } \\
\hline JBY25-4M & CEN.PK2-1C & $\begin{array}{l}\text { BsaraA, EcaraB, } \\
\text { EcaraD, ScGAL2 }\end{array}$ & - & Minimal & 20 & OL & 6 & 0.3 & [36] \\
\hline BWY1-4S & CEN.PK2-1C & $\begin{array}{l}\text { BsaraA, EcaraB, } \\
\text { EcaraD, ScGAL2 }\end{array}$ & $\begin{array}{l}\text { Codon optimization } \\
\text { Adaptive evolution }\end{array}$ & Minimal & 30 & AN & 9 & 0.39 & [43] \\
\hline IMS0002 & CEN.PK2-1C & $\begin{array}{l}\text { LparaA, LparaB, } \\
\text { LparaD }\end{array}$ & $\begin{array}{l}\text { PPP overexpression } \\
\text { Adaptive evolution }\end{array}$ & Complex & 20 & AN & 8.92 & 0.45 & [30] \\
\hline BSW3AP & CEN.PK102-3A & $\begin{array}{l}\text { LparaA, LparaB, } \\
\text { LparaD }\end{array}$ & $\begin{array}{l}\text { PPP overexpression } \\
\text { Adaptive evolution }\end{array}$ & Minimal & 20 & $\begin{array}{l}\text { OL } \\
\text { AN }\end{array}$ & $\begin{array}{c}6.9 \\
-\end{array}$ & $\begin{array}{l}0.43 \\
0.42\end{array}$ & [37] \\
\hline BSW3AG & CEN.PK102-3A & $\begin{array}{l}\text { LparaA, LparaB, } \\
\text { LparaD, ScGAL2 }\end{array}$ & $\begin{array}{l}\text { PPP overexpression } \\
\text { Adaptive evolution }\end{array}$ & Minimal & 20 & AN & - & 0.43 & [37] \\
\hline
\end{tabular}

OL, oxygen-limited conditions; AN, anaerobic conditions; Bs, Bacillus subtilis; Ec, Escherichia coli; Sc, Saccharomyces cerevisiae; Tr, Trichoderma reesei; Am, Ambrosiozyma monospora; Pi, Piromyces sp.; Lp, Lactobacillus plantarum; Nc, Neurospora crassa; Mt, Myceliophthora thermophile; Ss, Scheffersomyces stipitis; PPP, pentose phosphate pathway.

functionally identified as mannitol dehydrogenase [42]. Another factor determining L-arabinose fermentation efficiency is aeration. The fungal L-arabinose pathway is not redox-neutral because of the dual cofactor preference of AR and LXR (NADPH and NADH) while XDH and LAD are $\mathrm{NAD}^{+}$-specific. Therefore, the cofactor imbalance issue could be more severe than xylose fermentation requiring just $\mathrm{AR}$ and $\mathrm{XDH}$.

Meanwhile, the bacterial L-arabinose pathway is redoxneutral; thus, more studies have been performed for heterologous expression in $S$. cerevisiae from genes of Bacillus subtilis, Escherichia coli and Lactobacillus plantarum. The bacterial L-arabinose pathway consisting of araA, araB and $a r a D$ genes was tested with various combinations from different origins (Table 3). The araA gene from Bacillus subtilis [36], Bacillus licheniformis [43, 44] and Lactobacillus plantarum [30, 37] and the $\operatorname{araB}$ and $\operatorname{araD}$ genes from Escherichia coli $[43,44]$ or L. plantarum $[30,37]$ were tested. Ethanol production from the engineered strains varied between 6-9 g/1 from $20 \mathrm{~g} / 1 \mathrm{~L}$-arabinose. Regardless of the origin of the heterologous genes, various approaches to improve L-arabinose fermentation have been performed. In general, the overexpression of the non-oxidative pentose phosphate pathway genes (TAL1, TKL1, RPE1 and RKI1) and adaptive evolution were required [30, 36, 43]. However, despite all optimizations, the fermentation productivity is limited by a bacterial pathway possibly because of the unfavorable thermodynamic properties of L-arabinose isomerase under ambient conditions [45].

It should be noted that adaptive evolution is proven to be an effective metabolic engineering strategy to improve xylose fermentation by engineered $S$. cerevisiae strains for both fungal and bacterial pathways $[20,46]$. However, for L-arabinose fermentation, only the engineered strains with a bacterial pathway have been subjected to adaptive evolution (Table 2). It can be explained by the fact that L-arabinose fermentation has not been performed systematically and extensively compared to xylose fermentation. It is also possible that the heterologous expression of a fungal pathway in S. cerevisiae requires multiple strategies to be optimized to overcome the severe redox imbalance issue.

Arabinose fermentation can be improved by expressing L-arabinose-specific sugar transporters (Table 4). S. cerevisiae 
Table 4. Characterization of putative arabinose transporters over-expressed in a hexose transporter null mutant of Saccharomyces cerevisiae.

\begin{tabular}{lccc}
\hline \multicolumn{1}{c}{ Transporter genes } & Arabinose uptake rate $(\mathrm{mmol} / \mathrm{h} / \mathrm{g} \mathrm{DCW})$ & Arabinose affinity $(\mathrm{mM})$ & References \\
\hline Neurospora crassa LAT-1 & 116.7 & 58.12 & {$[50]$} \\
Myceliophthora thermophile LAT-1 & 10.29 & 29.39 & {$[50]$} \\
Penicillium chrysogenum AraT & 5.30 & 0.13 & {$[51]$} \\
Saccharomyces cerevisiae GAL2 & 0.13 & 57.00 & {$[48]$} \\
Arabidopsis thaliana Stp2 & 0.04 & 4.50 & {$[48]$} \\
Scheffersomyces stipites AraT & 0.02 & 3.80 & {$[48]$} \\
\hline
\end{tabular}

could uptake arabinose through some hexose transporters such as Hxt5 and Hxt7 with low affinity [47]. S. cerevisiae Gal2 had the highest affinity to L-arabinose $(57 \mathrm{mM})$ among other native hexose transporters [48, 49]. It is also reported that $S$. cerevisiae Gal2 contributed to anaerobic arabinose fermentation when arabinose is the sole carbon source [37]. Several heterologous arabinose transporters have been identified from Neurospora crassa [50], Myceliophthora thermophile [50], Penicillium chrysogenum [51], Arabidopsis thaliana [48], and Scheffersomyces stipitis [48], and their ability to uptake L-arabinose varies significantly (0.02$116.7 \mathrm{mmol} / \mathrm{h} / \mathrm{g}$ DCW). N. crassa LAT-1 was the most efficient L-arabinose transporter reported with a rate of 116.7 (mmol/h/g DCW), which is 2 orders of magnitude higher than that of S. cerevisiae GAL2 0.13 (mmol/h/g DCW) [50]. P. chrysogenum AraT was a high-affinity arabinose transporter with no activity with glucose and xylose, although it was still inhibited by the presence of glucose and xylose [51,52]. At the present stage, no heterologous sugar transporter was reported to either improve Larabinose fermentation or allow simultaneous uptake of arabinose and glucose. In arabinose metabolism, as in xylose's case $[53,54]$, it can be assumed that arabinose catabolism is currently more limiting than non-specific arabinose uptake in engineered $S$. cerevisiae.

\section{Engineering of Other Microorganisms for Arabinose Fermentation}

Some non-native arabinose fermenting microorganisms have also been engineered to assimilate L-arabinose and produce ethanol or other products. Z. mobilis (pZB206), which natively carries $p d c$ and $a d h B$ but lacked arabinoseassimilating enzymes, was constructed by introducing E. coli ara $A B D$, talB, tktA to metabolize arabinose to ethanol [55]. The resulting strain showed an ethanol yield of 0.49 by consuming $25 \mathrm{~g} / 1$ L-arabinose. Unlike S. cerevisiae, Corynebacterium glutamicum expressing E. coli araABD was easily engineered to produce amino acids such as Lglutamate, L-lysine, L-ornithine and L-arginine with arabinose as the sole carbon source [56]. For example, one of the engineered $C$. glutamicum strains produced L-glutamate at a yield of 0.07 from $75 \mathrm{~g} / 1$ L-arabinose. Rhodococcus opacus expressing Streptomyces cattleya araABD fermented $16 \mathrm{~g} / \mathrm{l}$ L-arabinose as the sole carbon source and produced fatty acids at a yield of 0.13 ( $\mathrm{g} / \mathrm{g}$ consumed arabinose). The fatty acids were mostly palmitic acid with some cis-10heptadecenoic acid, oleic acid, myristic acid, pentadecanoic acid, palmitoleic acid, heptadecanoic acid, and stearic acid. Although the examples are limited, non-Saccharomyces cerevisiae strains can also be engineered to ferment L-arabinose and produce various value-added products other than ethanol.

\section{Future Outlook}

Both crop biomass and cellulosic biomass do not support sustainable bioprocesses due to their low contribution to greenhouse gas reduction [57] and limited technologies to overcome the recalcitrance [58], respectively. Alternatively, pectin-rich biomass such as fruit-processing wastes can be an attractive choice due to low lignin content and the growing demands for fresh juice. L-Arabinose is a primary sugar of pectin structure and its content is minimal in other biomass. As discussed in this review, research for L-arabinose fermentation is in an early stage. Thus, all options are open to either optimizing native arabinoseassimilating strains or engineering non-native strains such as S. cerevisiae, Z. mobilis, C. glutamicum, and R. opacus depending on the desired products. Engineered S. cerevisiae strains fermenting L-arabinose are still limited to ethanol production, however, various chemicals and value-added 
products are expected to be studied as well. Additionally, the development of strains fermenting other pectin-derived monomers such as galacturonic acid and L-rhamnose needs to be considered.

\section{Acknowledgments}

This work was carried out with the support of the "Cooperative Research Program for Agriculture Science \& Technology Development (Project No. PJ01279801)" Rural Development Administration, Republic of Korea.

\section{Conflict of Interest}

The authors have no financial conflicts of interest to declare.

\section{References}

1. Robertson GP, Hamilton SK, Barham BL, Dale BE, Izaurralde RC, Jackson RD, et al. 2017. Cellulosic biofuel contributions to a sustainable energy future: choices and outcomes. Science 356(6345).

2. Gírio FM, Fonseca C, Carvalheiro F, Duarte LC, Marques S, Bogel-Łukasik R. 2010. Hemicelluloses for fuel ethanol: a review. Bioresour. Technol. 101: 4775-4800.

3. Go AR, Ko JW, Lee SJ, Kim SW, Han SO, Lee J, et al. 2012. Process design and evaluation of value-added chemicals production from biomass. Biotechnol. Bioprocess Eng. 17: 1055-1061.

4. Trinh LTP, Lee Y-J, Lee J-W, Lee W-H. 2018. Optimization of ionic liquid pretreatment of mixed softwood by response surface methodology and reutilization of ionic liquid from hydrolysate. Biotechnol. Bioprocess Eng. 23: 228-237.

5. Alonso DM, Hakim SH, Zhou S, Won W, Hosseinaei O, Tao J, et al. 2017. Increasing the revenue from lignocellulosic biomass: maximizing feedstock utilization. Science Adv. 3: e1603301.

6. Liao JC, Mi L, Pontrelli S, Luo S. 2016. Fuelling the future: microbial engineering for the production of sustainable biofuels. Nat. Rev. Microbiol. 14: 288-288.

7. Wei N, Quarterman J, Jin YS. 2013. Marine macroalgae: an untapped resource for producing fuels and chemicals. Trends Biotechnol. 31: 70-77.

8. Park M-R, Kim S-K, Jeong G-T. 2018. Biosugar production from Gracilaria verrucosa with sulfamic acid pretreatment and subsequent enzymatic hydrolysis. Biotechnol. Bioprocess Eng. 23: 302-310.

9. Javier AG, Maria Cristina R, Oriana S, Maria Elena L. 2018. Saccharification of brown macroalgae using an arsenal of recombinant alginate lyases: potential application in the biorefinery process. J. Microbiol. Biotechnol. 28: 1671-1682.
10. Oh YR, Jung KA, Lee HJ, Jung GY, Park JM. 2018. A novel 3,6-anhydro-L-galactose dehydrogenase produced by a newly isolated Raoultella ornithinolytica B6-JMP12. Biotechnol. Bioprocess Eng. 23: 64-71.

11. Van Dyk JS, Gama R, Morrison D, Swart S, Pletschke BI. 2013. Food processing waste: problems, current management and prospects for utilisation of the lignocellulose component through enzyme synergistic degradation. Renew. Sustain. Energy Rev. 26: 521-531.

12. Lisandro GS, Raul NC, Maria TB, Miguel AI. 2018. Feasibility of bioethanol production from cider waste. J. Microbiol. Biotechnol. 28: 1493-1501.

13. Edwards MC, Doran-Peterson J. 2012. Pectin-rich biomass as feedstock for fuel ethanol production. Appl. Microbiol. Biotechnol. 95: 565-575.

14. Choi IS, Lee YG, Khanal SK, Park BJ, Bae HJ. 2015. A lowenergy, cost-effective approach to fruit and citrus peel waste processing for bioethanol production. App. Energy 140: 65-74.

15. May CD. 1990. Industrial pectins: Sources, production and applications. Carbohydr. Polym. 12: 79-99.

16. Seiboth B, Metz B. 2011. Fungal arabinan and L-arabinose metabolism. Appl. Microbiol. Biotechnol. 89: 1665-1673.

17. Oosterveld A, Beldman G, Schols HA, Voragen AGJ. 1996. Arabinose and ferulic acid rich pectic polysaccharides extracted from sugar beet pulp. Carbohydr. Res. 288: 143-153.

18. Müller-Maatsch J, Bencivenni M, Caligiani A, Tedeschi T, Bruggeman G, Bosch M, et al. 2016. Pectin content and composition from different food waste streams in memory of Anna Surribas, scientist and friend. Food Chem. 201: 37-45.

19. van Maris AJA, Abbott DA, Bellissimi E, van den Brink J, Kuyper M, Luttik MAH, et al. 2006. Alcoholic fermentation of carbon sources in biomass hydrolysates by Saccharomyces cerevisiae: current status. Antonie Van Leeuwenhoek Int. J. Gen. Mol. Microbiol. 90: 391-418.

20. Kim SR, Park YC, Jin YS, Seo JH. 2013. Strain engineering of Saccharomyces cerevisiae for enhanced xylose metabolism. Biotechnol. Adv. 31: 851-861.

21. Hahn-Hägerdal B, Karhumaa K, Fonseca C, Spencer-Martins I, Gorwa-Grauslund MF. 2007. Towards industrial pentosefermenting yeast strains. Appl. Microbiol. Biotechnol. 74: 937-953.

22. Servinsky MD, Germane KL, Liu S, Kiel JT, Clark AM, Shankar J, et al. 2012. Arabinose is metabolized via a phosphoketolase pathway in Clostridium acetobutylicum ATCC 824. J. Ind. Microbiol. Biotechnol. 39: 1859-1867.

23. Fonseca C, Romão R, Rodrigues De Sousa H, HahnHägerdal B, Spencer-Martins I. 2007. L-Arabinose transport and catabolism in yeast. FEBS J. 274: 3589-3600.

24. Verho R, Putkonen M, Londesborough J, Penttilä M, Richard P. 2004. A novel NADH-linked L-xylulose reductase in the L-arabinose catabolic pathway of yeast. J. Biol. Chem. 279: 14746-14751.

25. Fonseca C, Spencer-Martins I, Hahn-Hägerdal B. 2007. LArabinose metabolism in Candida arabinofermentans PYCC 
5603T and Pichia guilliermondii PYCC 3012: influence of sugar and oxygen on product formation. Appl. Microbiol. Biotechnol. 75: 303-310.

26. McMillan JD, Boynton BL. 1994. Arabinose utilization by xylose-fermenting yeasts and fungi. Appl. Biochem. Biotechnol. 45-46: 569-584.

27. Watanabe S, Kodak T, Makino K. 2006. Cloning, expression, and characterization of bacterial L-arabinose 1-dehydrogenase involved in an alternative pathway of L-arabinose metabolism. J. Biol. Chem. 281: 2612-2623

28. Dien BS, Kurtzman CP, Saha BC, Bothast RJ. 1996. Screening for L-arabinose fermenting yeasts. Appl. Biochem. Biotechnol. 57-58: 233-242.

29. Kurtzman CP, Dien BS. 1998. Candida arabinofermentans, a new L-arabinose fermenting yeast. Antonie Van Leeuwenhoek Int. J. Gen. Mol. Microbiol. 74: 237-243.

30. Wisselink HW, Toirkens MJ, Berriel MDRF, Winkler AA, Van Dijken JP, Pronk JT, et al. 2007. Engineering of Saccharomyces cerevisiae for efficient anaerobic alcoholic fermentation of L-arabinose. Appl. Environ. Microbiol. 15: 488-491.

31. Finn RK, Bringer S, Sahm H. 1984. Fermentation of arabinose to ethanol by Sarcina ventriculi. Appl. Microbiol. Biotechnol. 19: 161-166.

32. Bothast RJ, Saha BC, Flosenzier V, Ingram LO. 1994. Fermentation of L-arabinose, D-xylose and D-glucose by ethanologenic recombinant Klebsiella oxytoca strain P2. Biotechnol. Lett. 16: 401-406.

33. Dien BS, Hespell RB, Wyckoff HA, Bothast RJ. 1998. Fermentation of hexoses and pentoses sugars using a novel ethanologenic Escherichia coli strain. Enzyme Microb. Technol. 23: 366-371.

34. Richard P, Verho R, Putkonen M, Londesborough J, Penttilä M. 2003. Production of ethanol from L-arabinose by Saccharomyces cerevisiae containing a fungal L-arabinose pathway. FEMS Yeast Res. 3: 185-189.

35. Bera AK, Sedlak M, Khan A, Ho NWY. 2010. Establishment of L-arabinose fermentation in glucose/xylose co-fermenting recombinant Saccharomyces cerevisiae 424A(LNH-ST) by genetic engineering. Appl. Microbiol. Biotechnol. 87: 1803-1811.

36. Becker J, Boles E. 2003. A modified Saccharomyces cerevisiae strain that consumes L-arabinose and produces ethanol. Appl. Environ. Microbiol. 69: 4144-4150.

37. Wang C, Shen Y, Zhang Y, Suo F, Hou J, Bao X. 2013. Improvement of L-arabinose fermentation by modifying the metabolic pathway and transport in Saccharomyces cerevisiae. Biomed. Res. Int. 2013:461204.

38. Wang C, Zhao J, Qiu C, Wang S, Shen Y, Du B, et al. 2017. Coutilization of D-glucose, D-xylose, and L-arabinose in Saccharomyces cerevisiae by coexpressing the metabolic pathways and evolutionary engineering. Biomed. Res. Int. 2017: 5318232.
39. Bettiga M, Bengtsson O, Hahn-Hägerdal B, Gorwa-Grauslund MF. 2009. Arabinose and xylose fermentation by recombinant Saccharomyces cerevisiae expressing a fungal pentose utilization pathway. Microb. Cell Fact. 8: 1-12.

40. Watanabe S, Utsumi Y, Sawayama S, Watanabe Y. 2016. Identification and characterization of D-arabinose reductase and D-arabinose transporters from Pichia stipitis. Biosci. Biotechnol. Biochem. 80: 2151-2158.

41. Richard P, Putkonen M, Väänänen R, Londesborough J, Penttilä M. 2002. The missing link in the fungal L-arabinose catabolic pathway, identification of the L-xylulose reductase gene. Biochem. 41: 6432-6437.

42. Metz B, de Vries RP, Polak S, Seidl V, Seiboth B. 2009. The Hypocrea jecorina (syn. Trichoderma reesei) lxr1 gene encodes a d-mannitol dehydrogenase and is not involved in Larabinose catabolism. FEBS Lett. 583: 1309-1313.

43. Wiedemann B, Boles E. 2008. Codon-optimized bacterial genes improve L-arabinose fermentation in recombinant Saccharomyces cerevisiae. Appl. Environ. Microbiol. 74: 2043-2050.

44. Wang X, Yang J, Yang S, Jiang Y. 2019. Unraveling the genetic basis of fast l-arabinose consumption on top of recombinant xylose-fermenting Saccharomyces cerevisiae. Biotechnol. Bioeng. 116: 283-293.

45. Lee DW, Hong YH, Choe EA, Lee SJ, Kim SB, Lee HS, et al. 2005. A thermodynamic study of mesophilic, thermophilic, and hyperthermophilic L-arabinose isomerases: the effects of divalent metal ions on protein stability at elevated temperatures. FEBS Lett. 579: 1261-1266.

46. Jansen MLA, Bracher JM, Papapetridis I, Verhoeven MD, de Bruijn H, de Waal PP, et al. 2017. Saccharomyces cerevisiae strains for second-generation ethanol production: from academic exploration to industrial implementation. FEMS Yeast Res. 17: fox044.

47. Leandro MJ, Fonseca C, Gonçalves P. 2009. Hexose and pentose transport in ascomycetous yeasts: An overview. FEMS Yeast Res. 9: 511-525.

48. Subtil T, Boles E. 2011. Improving L-arabinose utilization of pentose fermenting Saccharomyces cerevisiae cells by heterologous expression of L-arabinose transporting sugar transporters. Biotechnol. Biofuels 4: 1-10.

49. Verhoeven MD, Bracher JM, Nijland JG, Bouwknegt J, Daran JG, Driessen AJM, et al. 2018. Laboratory evolution of a glucose-phosphorylation-deficient, arabinose-fermenting S. cerevisiae strain reveals mutations in GAL2 that enable glucose-insensitive l-arabinose uptake. FEMS Yeast Res. 18: doi: $10.1093 /$ femsyr / foy062.

50. Li J, Xu J, Cai P, Wang B, Ma Y, Benz JP, et al. 2015. Functional analysis of two L-arabinose transporters from filamentous fungi reveals promising characteristics for improved pentose utilization in Saccharomyces cerevisiae. Appl. Environ. Microbiol. 81: 4062-4070.

51. Bracher JM, Verhoeven MD, Wisselink HW, Crimi B, Nijland JG, Driessen AJM, et al. 2018. The Penicillium 
chrysogenum transporter Pc AraT enables high-affinity, glucose-insensitive L-arabinose transport in Saccharomyces cerevisiae. Biotechnol. Biofuels 11:63.

52. Verhoeven MD, de Valk SC, Daran JG, van Maris AJA, Pronk JT. 2018. Fermentation of glucose-xylose-arabinose mixtures by a synthetic consortium of single-sugar-fermenting Saccharomyces cerevisiae strains. FEMS Yeast Res. 18: doi: 10.1093/femsyr/foy075.

53. Kim SR, Ha S-J, Wei N, Oh EJ, Jin Y-S. 2012. Simultaneous co-fermentation of mixed sugars: a promising strategy for producing cellulosic ethanol. Trends Biotechnol. 30: 274-282.

54. Lane $\mathrm{S}, \mathrm{Xu} \mathrm{H}$, Oh EJ, Kim H, Lesmana A, Jeong D, et al. 2018. Glucose repression can be alleviated by reducing glucose phosphorylation rate in Saccharomyces cerevisiae. Sci. Rep. 8: 2613.
55. Deanda K, Zhang MIN, Eddy C, Picataggio S. 1996. Development of an arabinose-fermenting Zymomonas mobilis strain by metabolic pathway engineering. Microbiol. 62: 4465-4470.

56. Schneider J, Niermann K, Wendisch VF. 2011. Production of the amino acids L-glutamate, L-lysine, L-ornithine and Larginine from arabinose by recombinant Corynebacterium glutamicum. J. Biotechnol. 154: 191-198.

57. Searchinger T, Heimlich R, Houghton RA, Dong F, Elobeid A, Fabiosa J, et al. 2008. Use of U.S. croplands for biofuels increases greenhouse gases through emissions from landuse change. Science 423: 1238-1241.

58. Lynd LR. 2017. The grand challenge of cellulosic biofuels. Nat. Biotechnol. 35: 912-915. 